\title{
RELAÇÃO ENTRE ARTE, DESIGN E ARTEFATO A PARTIR DA OBRA DE ROCHELLE COSTI
}

\author{
Relation between art, design and artifact from the work of Rochelle Costi
}

OLIVEIRA, Deise Aparecidade; Especialização em Gestão Escolar, Séries Iniciais - UNIASSELVI; Programa de Pós-Graduação e, Tecnologia e Sociedade (UTFPR/PPGTE)

deise.1927@gmail.com

SILVEIRA, Luciana Martha, Doutroa em Comunicação e Semiótica - PUC-SP; Programa de PósGraduação e, Tecnologia e Sociedade (UTFPR/PPGTE)

silveira.lucianam@gmail.com

\section{Resumo}

O artigo tem como objetivo aproximar o diálogo entre arte, design e antropologia, discutindo a cultura material, bem como a construção do artefato e do objeto de arte, a partir da obra de Rochelle Costi. Para realizar esse debate, o referencial teórico utilizado está pautado nos autores Canclini(2008,2013,2015), Miller(2013), Appadurai(2008), Danto(2005), Cardoso(2013), Martins(2017) e Mendes(2012) por sustentarem como esse diálogo tem, na atualidade, se aprofundado e dado visibilidade aos processos de construção social, simbólica e cultural, algo que a arte já possibilita há anos. Evidenciar essa discussão permite entender que os objetos se constituem no processo de usos, sendo significados e ressignificados ao longo de suas trajetórias. Dessa forma, é possível pensar na destituição da funcionalidade aplicada ao design e observar outras possibilidades que são construídas na atualidade.

Palavras Chave: cultura material, usos, arte, artefato, mediação tecnológica.

\begin{abstract}
The article aims to approach the dialogue between art, design and anthropology, discussing material culture, as well as the construction of the artifact and the object of art, from the work of Rochelle Costi. In order to carry out this debate, the theoretical reference used is based on the authors Canclini(2008,2013,2015), Miller(2013), Appadurai(2008), Danto(2005), Cardoso(2013), Martins(2001) and Mendes(2012) for sustaining how this dialogue has, at the present time, deepened and given visibility to the process of social, symbolic and cultural construction, something that art has made possible for years. To evidence this discussion allows us to understand that the objects are constituted in the process of uses, being defined and redefined along their trajectories. In this way, it is possible to think about the destitution of the functionality applied to the design and observe other possibilities that are constructed in these days.
\end{abstract}

Keywords: material culture, art, artifact, technology mediation. 


\section{Introdução}

Um objeto pode ser projetado, percebido ou interpretado como objeto de design, obra de arte, artefato, treco, coisa, mercadoria, assim como outras denominações. Nesse contexto, as teorias de cultura material, na atualidade, discutem essas designações a partir de várias óticas. Mendes (2012) ao refletir sobre os artefatos aponta:

Ao deixar marcas e rastros - reais ou metafóricos - a cultura material significa, testemunha e materializa a construção de histórias, identidades, lugares, épocas e formas de viver. As marcas, ilustres, anônimas, deixam sinais de culturas, revelam modelos de relacionamento entre sujeitos, destes com as coisas e com a vida em sociedade. (MENDES, 2012,p.16).

Dentro das áreas específicas, a Teoria da Arte, há muito tempo, discute o que é o objeto de arte. Na contemporaneidade essa discussão foi intensificada com Artur Danto. Em A Transfiguração do Lugar-comum (2005), o autor discute os ready-mades, especificamente a Brillo Box de Andy Warhol, em que Danto(2005) evidencia

essa transformação de um objeto banal não transforma coisa alguma no mundo da arte. Ela simplesmente traz à luz da consciência as estruturas da arte, o que sem dúvida pressupõe que tenha havido um certo desenvolvimento histórico para que a metáfora fosse possível.(DANTO, 2005,p.297).

O argumento referente à discussão sobre o que viria a ser uma obra de arte em Danto(2005) é pautado na premissa que a obra de arte é histórica, bem como que há um campo filosófico que determina o que pode ser, ou não, obra de arte. Este argumento tem sido discutido por autores como Alfred Gell, que constrói seus pensamentos a partir de artefatos retirados de outros contextos, como o de culturas ágrafas. Precisamente esses contextos, onde estão alocados os objetos que esse autor utiliza para construir seus conceitos e argumentos para discutir com Danto, são sociedades que dão outros significados para os objetos, nas quais o conceito de arte que a cultura ocidental possui, não faz sentido. Sendo assim, essa discussão ganha cada vez mais espaço e as fronteiras se tornam mais diluídas entre as categorias conhecidas, entrando em negociações e algumas vezes sofrendo alterações.

Neste artigo pretende-se discutir a relação entre a arte, o design e o artefato a partir de autores da Antropologia e da Teoria de Arte, evidenciando, com o fundamento da biografia social das coisas, a necessidade de aproximarmos campos teóricos para visibilizar os processos e a interdisciplinaridade que a obra de arte permite. A escolha da artista Rochelle Costi é ponto de experimentação na discussão, pois a artista escolhe objetos retirados do cotidiano, como Duchamp com seus ready-mades, os ressignificando na atualidade. Os objetos de Costi são transformados em outros objetos, em fotografias, que problematizam o cotidiano, criam novos significados e relações que se estabelecem a partir dessa mediação.

\section{A trajetória dos objetos}

O que acontece se deixarmos de prestar atenção apenas nos vínculos sociais que supostamente precedem ou deveriam preceder as coisas, e começarmos a observar as coisas durante os variados percursos e trajetórias 
que elas fazem e traçam, na sociedade por meio das diferentes esferas de circulação nela existentes? (GOMES, 2008, p.10).

Essa questão surge justamente na introdução do livro A Vida Social das Coisas (1988), que foi a conclusão de duas convenções, em 1986 e 1987, em que autores como Igor Kopytoff, discutiam a partir dessa perspectiva, a importância de se pensar em uma antropologia das coisas. Arjun Appadurai, nesse livro, parte das proposições sobre o que pode ou não ser mercadoria, uma vez que o objeto pode ou não ser acionado como mercadoria em seu percurso. Miller (2013), em Trecos, troços e coisas, apresenta outras proposições. O autor pensa nas possibilidades que se estabelecem a partir da relação do humano com o não humano na atualidade. Em sua teoria de objetificação, Miller(2013, p.88) diz que "o que temos é o processo dinâmico ele mesmo, que produz simultaneamente aquilo que passamos a mencionar coloquialmente como objetos e sujeitos." Esses textos possibilitam pensar a trajetória dos objetos produzidos por Rochelle Costi e as interfaces que os mesmos suscitam, desconstruindo a categorização estanque entre objeto de arte e artefato.

Para esse artigo, a artista escolhida é Rochelle Costi (1961), que trabalha desde a década de 80 do século $X X$, na produção de imagens. A artista produz seu trabalho em diferentes suportes, como: fotografias, vídeos, instalações, entre outras proposições, a partir de objetos de sua coleção pessoal ou retirados dos locais que escolhe para expor.

Rochelle Costi (1961) é natural de Caxias do Sul no Rio Grande do Sul. Nos anos 1980 frequentou a Escola Guignard, em Belo Horizonte e morou em Londres entre 1991 e 1992. Foi à São Paulo fazer um estágio de algumas semanas com o fotógrafo Bob Wolfenson, parceria que durou 7 meses. Desde a década de 1990 a artista reside em São Paulo. Sua trajetória artística se configurou como sólida ao longo dos anos, expondo em importantes espaços como Museu de Arte Moderna em Buenos Aires, Museu de Arte Contemporânea de São Francisco/Califórnia, Bienal do Mercosul, Bienal de Havana/Cuba, Bienal Internacional de Arte de São Paulo, entre outros.

Sua história pessoal é marcada por um acontecimento: a artista relata que um dia amanheceu vesga e esse fato mudou sua história, pois passou por várias correções da visão enquanto criança, o que, segundo a artista, mudou a forma de ver e pensar o mundo à sua volta (Catálogo Galeria Brito Cimino, 2005). A artista é uma colecionadora de objetos, bem como está imersa no universo da arte. Esses traços estão presentes em seu trabalho, que cria composições com esses objetos, pautada nas relações com a História da Arte e os referenciais que construiu ao longo de sua trajetória. Esses objetos, que são retirados de mais diversos contextos, permitem pensar suas trajetórias e a constituição como objeto de arte, como aponta Mendes (2012):

Significados dos objetos, seus usos, permanências e metamorfoses articulam sentidos de ser no mundo. $\mathrm{O}$ que valorizamos acaba reforçando, configurando e/ou transformando nossos comportamentos e estilos de vida, convertendo-se em modos de compreender, vivenciar e valorizar o mundo e o que o constitui. (MENDES, 2012,p.17).

A artista se interessa pelo universo íntimo e a relação que o ser humano tem com os objetos que o cerca. Esses interesses são registrados na fotografia ou, muitas vezes, resultam em instalações, trazendo para o espaço de exposição objetos retirados do cotidiano, da cultura popular, ou mesmo as ações das pessoas que figuram nesse universo. O interesse por essa relação está diretamente ligado ao que denominamos como cultura material, pois é na relação com os objetos que estes se constroem e, em última análise, o próprio ser humano é constituído. As imagens e instalações da artista possuem poucos corpos representados, algo que chama a atenção. É o corpo do público que precisa estar em contato com a obra e ser de alguma forma obrigado a se mover, a 
se exercitar, a olhar por um local específico, a completar a obra. Mas, fica evidente que não é o corpo o assunto dos seus trabalhos, o que reforça o interesse da artista pela condição do ser humano na relação com o mundo que o cerca.

A artista escolhe a fotografia para desenvolver seu trabalho, com o que Barthes (1984) chama de punctum: aquilo que punge e torna singular a imagem criada, que vive fora da imagem e passa a habitar nosso imaginário, gerando outras imagens e narrativas.

A Série escolhida para esse artigo é Quartos-São Paulo de 1998, feita para a XXIV Bienal Internacional de Arte de São Paulo, apresentada no núcleo "Um entre Outros", sob a curadoria de Paulo Herkenhoff. Essa série foi construída para esse espaço, por conta do financiamento do Prêmio da FUNARTE, que a artista foi contemplada, o que possibilitou a execução do projeto. A Série é um desdobramento de outros trabalhos da década de 1990, que pensavam a forma de morar, o espaço íntimo e as relações com os objetos que compõem esses espaços. A seguir analisaremos algumas imagens que compõe a série e suas relações com as proposições do texto:

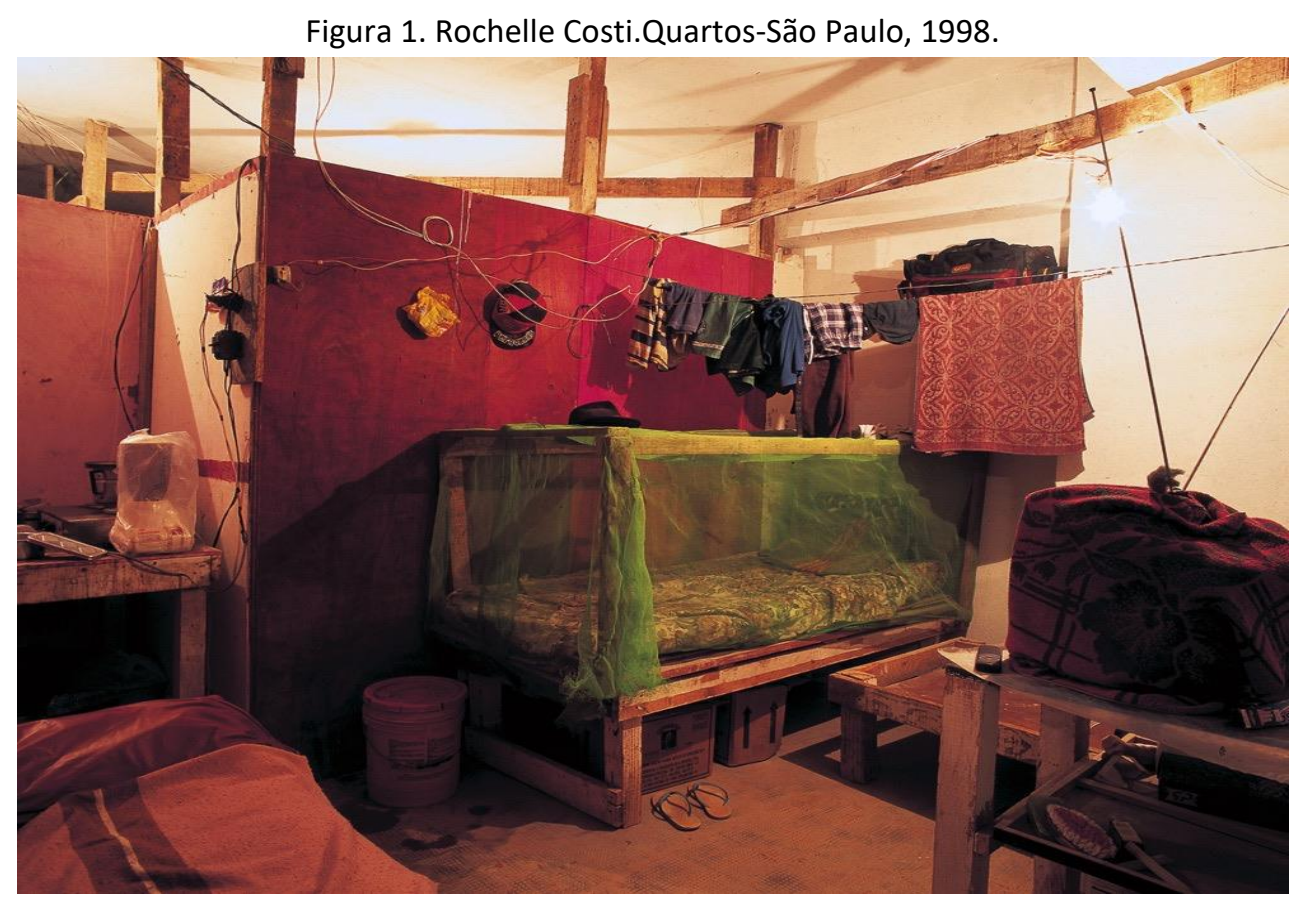

Fonte: http://rochellecosti.com/Quartos-Sao-Paulo-1998. Fotografia Analógica, 1x80m x 2,20m.

A partir de Joly (2000), a leitura da imagem se estruturou em três etapas: a primeira consiste em entender o que é reconhecível em cena, enquanto a segunda analisa os elementos, para na terceira interpretar, significar e ressignificar essa imagem. Nela é possível reconhecer vários elementos: fios, chinelos, boné, toalha, roupas penduradas em um fio, uma possível caixa envolta em um tecido verde, uma televisão coberta, algumas caixas, duas mesas, um recipiente cilíndrico. As paredes são feitas em algum material semelhante à madeira, num tom de vermelho para magenta, e logo, à frente, há essa estrutura com tom verde, que sendo complementares, causam certo estranhamento na visão. A luz do ambiente colabora com essa atmosfera, não se consegue distinguir se é dia ou noite, pois o ambiente não apresenta janelas, nem portas. Temos a noção do espaço, porém, não é possível completar a figura com exatidão. 
Por nosso olhar ser mediado por várias informações, como as revistas de decoração, lançamos um julgamento quando nos deparamos com a imagem: é de uma classe social que apresenta simplicidade nos objetos e em toda a cena, pode-se aferir que faltam recursos financeiros, é uma construção que serve como trânsito para um possível trabalhador e não sabemos se mora alguém no lugar. Em suma, lançamos várias hipóteses para o espaço.

A imagem tem um aspecto cenográfico, mesmo que se reconheça a precariedade do espaço, percebe-se uma preocupação em ter um lugar para cada objeto Isso denota uma atenção em morar, em ter ordem, em ter limpeza do espaço. Outro destaque pode ser dado aos vários objetos que estão cobertos, como a televisão com um cobertor, o que poderia ser a cama possui uma tela envolta, um liquidificador coberto com um plástico. Esses cuidados provoca o espectador a refletir sobre a ação humana no espaço, embora não haja humano em cena. Permite pensar ainda sobre a relação desse ser humano com esses objetos presentes na imagem. É a partir dos objetos organizados no espaço da cena que temos os indícios sobre a relação do ser humano com esse espaço. Se o artigo tivesse a intenção de tensionar as questões de gênero, até mesmo esses indícios estão presentes na imagem, como: cuecas ou o boné, o corte das camisetas no varal e as bermudas expostas. Esses elementos serviriam para a problematização, o que pode ser pontuado para posteriores discussões.

Quando se reflete sobre a produção de objetos para a composição de interiores, a moradia, se pensa na construção desses objetos em processo de pesquisas, concepção, criação, circulação, consumo, etapas de design. Outra atribuição sobre o objeto de design é a funcionalidade, discutida por Cardoso (2013). Segundo o autor essa característica designada aos objetos não faz mais sentido no que ele denomina como "mundo complexo". O autor defende a ideia que o objeto de design também reconhecido por ele como artefato - é ressignificado no seu uso social, assim como a imagem aqui apresentada. Observando a imagem é necessário se pensar a constituição desses objetos, como Mendes (2012) chama a atenção:

A cultura material abrange, pois, produtos coletivos da vida humana, mediadores de relações, constituídos em processos dinâmicos de externalização de indivíduos e sociedades na história. Envolve continuidades, contradições e rupturas na performatização cotidiana do ser e estar no mundo e no tempo. (MENDES, 2012, p.18).

Quem é a pessoa que habita esse espaço, como foi concebido, entre outros questionamentos a respeito dessa imagem são necessários, para o entendimento da construção social e simbólica, desse ambiente. Para essa Série, Rochelle Costi escolheu as casas a partir do mapeamento dos bairros de São Paulo. Propositadamente a artista escolheu casas que eram de bairros com classes sociais distintas, sendo bairros considerados nobres, classe média e classe baixa, de acordo com a renda per capita brasileira, a partir da segunda metade dos anos 90. A partir desse mapeamento, a escolha das casas se deu por indicação de pessoas conhecidas ou do trabalho de campo, do reconhecimento do local e permissão dos moradores, para o registro. Algumas pessoas prepararam o ambiente para ser fotografado e outras não, sendo flagradas no local, com a imagem sendo produzida com a luz natural do ambiente, sem a utilização de outros recursos.

A imagem 1 era a moradia temporária de um trabalhador da construção civil, que tendo o trabalho se estendido durante meses, montou sua casa junto à construção que estava trabalhando. Voltando à imagem, percebemos que essa informação direciona nosso olhar para a construção desse espaço e como estes objetos estão pensados nele. A coberta sobre a televisão, o varal dentro do ambiente, o plástico que envolve o liquidificador, as caixas embaixo da cama, a tela fina 
envolvendo a cama, todos esses elementos ganham outra dimensão, pois entendemos que nesse ambiente, são necessários cuidados com possíveis mosquitos, ratos, baratas e outros possíveis insetos. As caixas podem guardar objetos que, em outro contexto, poderiam estar em um guardaroupa. Os fios da eletricidade são temporários e provisórios. O fio que as roupas estão depositadas, seve como varal e é necessário dentro do ambiente, pois, é uma forma de garantir que não haverá material da construção sujando as roupas limpas. Ou seja, a pessoa está ausente na imagem, mas habita esse espaço, desenvolveu uma forma de morar. Mendes (2012) aponta a "materialidade oculta, revela acordos e tensões que significam as coisas, relacionando-as a práticas sociais, estilos de vida e as inserindo em políticas de valor".

Muitos dos objetos que aparecem no ambiente estão ressignificados, como uma coberta, que no caso desse quarto, envolve a televisão. Outro objeto que podemos destacar é a tela que aparece na fotografia envolvendo a cama. Essa tela é comumente vista nas construções civis, como proteção da estrutura, para as pessoas não serem atingidas por resíduos de cimento ou outros objetos, quando passam próximo à essas construções.

Cardoso (2013) aponta os objetos como artefatso, direcionando a discussão do objeto de design como objeto de uso social, pois para o autor, a significação se dá somente na relação que esse objeto propicia.

As formas dos artefatos não possuem um significado fixo, mas antes são expressivas de um processo de significação - ou seja, a troca entre aquilo que está embutido em sua materialidade e aquilo que pode ser depreendido delas por nossa experiência. Por um lado, as formas concretizam os conceitos por trás de sua criação. Para empregar um termo corrente hoje, os artefatos obedecem a uma "lógica construtiva", a qual é a soma das ideias contidas em seu projeto com seus materiais e condições de fabricação. Por outro lado, formas e artefatos são passíveis de adaptação pelo uso e sujeitos a mudanças de percepção pelo juízo. (CARDOSO, 2013,p.18)

A ressignificação desses objetos traz à tona os desvios que Kopytoff(2008) discute, pois esse autor pensa a singularização das coisas. Mendes(2012) dialoga com o autor apontando que:

Sem a devida contextualização e localização, modos da apropriação dos bens culturais podem considerar uma aparente univocidade dos produtos, podendo ser deixados de lado fatores que caracterizam distintos estilos de vida e distintos modelos de uso dos artefatos. (Mendes, 2012,p.19).

Ainda é possível buscar outras referências na História da Arte, como a série de Bólides de Hélio Oiticica (1937-1980) talvez seja a primeira referência que a imagem remeta: 
Figura 2. Hélio Oiticica. Detalhe da Obra "Cama 1".

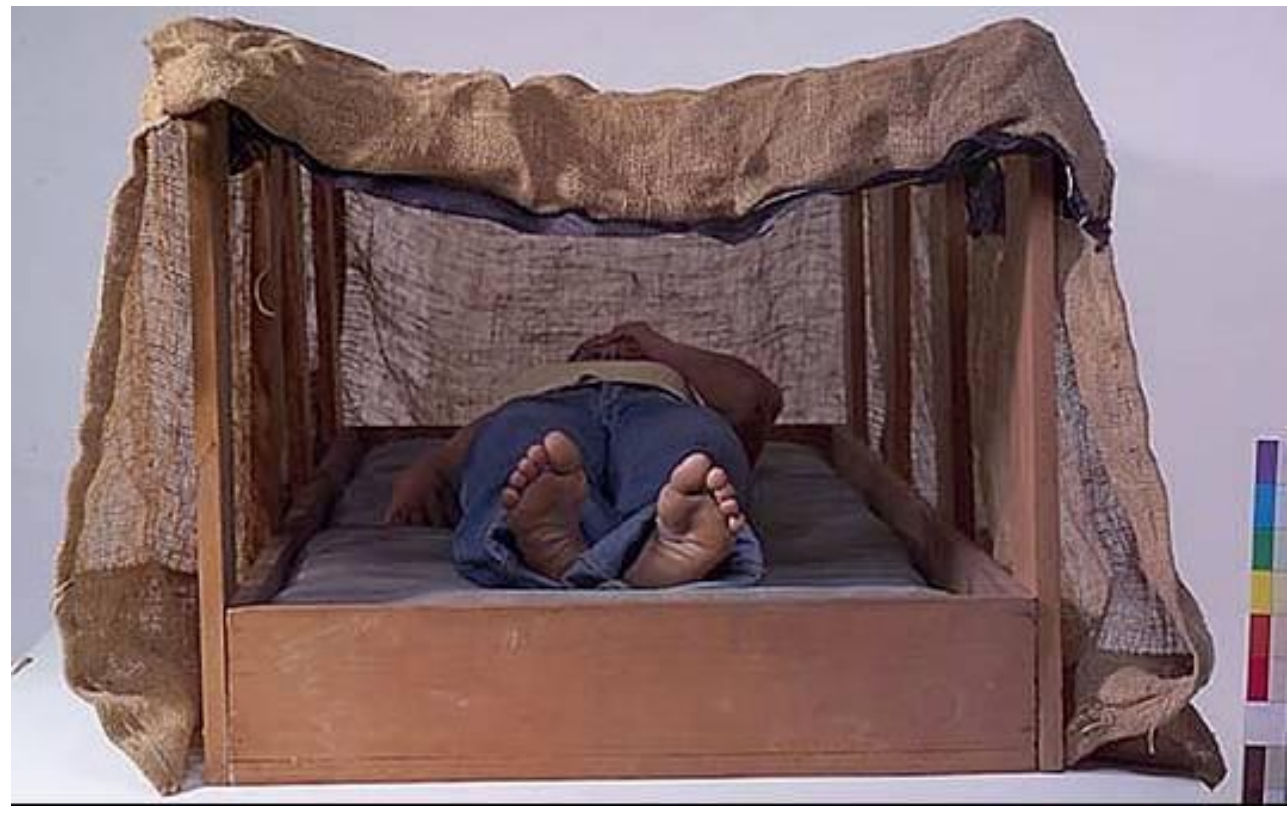

Fonte:http://g1.globo.com/Noticias/PopArte/0,,MUL1536870-7084,00-

EXPOSICAO+EM+SAO+PAULO+REUNE+CEM+OBRAS+DE+HELIO+OITICICA.html

Embora a artista não faça uma referência direta ao trabalho de Hélio Oiticica, a escolha da artista em fotografar e selecionar essa imagem pode ter sido contaminada pela produção do artista, pois Oiticica é um dos mais importantes artistas a partir da década de 1960 no Brasil. Suas obras são remontadas em várias exposições, dentro e fora do Brasil. Esse dado é uma forma de apontar para a produção da arte imersa culturalmente. Esses diálogos em Arte também são recorrentes, pois vimos em outros artistas as referências diretas, através do estudo de suas obras, tanto como homenagem, quanto elaboração de novos pensamentos. São muitos exemplos, destaca-se aqui Salvador Dali (1904-1989) em "O Mito Trágico de Ângelus de Millet (1932-1935)" e "L'Angelus (1888)" de Van Gogh, apresentando suas versão de "Angelus (1857-1859)" de Jean-François Millet (1814-1875), uma das obras mais revisitadas ao longo da História da Arte.

Para Geertz (2007, p.192) "o sistema de objetos que chamamos de arte só se torna possível por meio da participação no sistema geral de formas simbólicas que denominamos cultura." Como visto, a produção artística está imersa nos processos culturais a que pertence, cria e constrói, na medida que é construída.

Retomando a imagem em discussão, é possível relacionar outra referência na História da Arte, Joseph Beuys (1921-1986): 
Figura 3. Joseph Beuys. Infiltração homogênea para piano de calda, 1966.

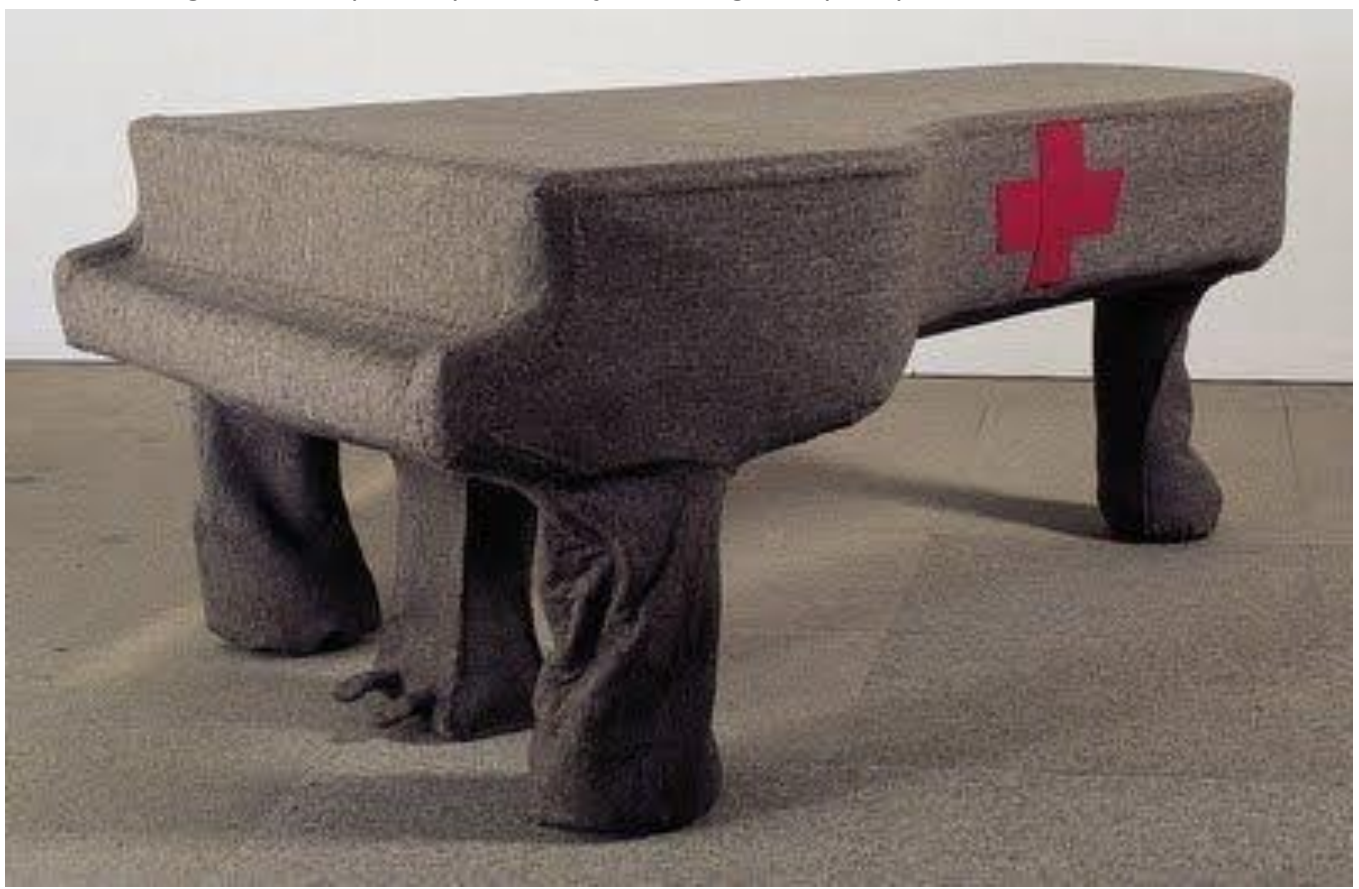

Fonte: https://artenomundo.wordpress.com/2010/11/15/joseph-beuys-atividade-cultural-07/.(2010)

Como dito anteriormente, essas relações são inferências que surgem no processo de leitura e possivelmente no processo de produção da imagem, pelo olhar treinado da artista, que quando em cena, produz novos significados e imagens, a partir dessas referências.

A construção dessas referências pode ser entendidas como consumo, pois, na atualidade, ele é pensado como parte do processo social. Bem como negociações que se estabelecem a partir de várias relações e não apenas pela criação de demanda, como até o início do Século XX. Canclini (2008) problematiza o consumo na arte contemporânea:

Muito do que é feito atualmente nas artes é produzido e circula de acordo com as regras das inovações e da obsolescência periódica, não por causa do impulso experimentador, como no tempo das vanguardas, mas sim por que as manifestações culturais foram submetidas aos valores que "dinamizam" o mercado e a moda: consumo incessantemente renovado, surpresa e divertimento. (CANCLINI, 2008, p.18).

Nessa citação está claro o descontentamento de Canclini(2008) com as manifestações artísticas na atualidade. $\mathrm{O}$ autor mostra a produção de arte como algo pensado para o mercado, entendido como venda e negociações diretas de valores e especulações, não atualizando o circuito de produção, circulação e consumo por pensamentos estéticos vanguardistas. Essa forma de consumo implica, no que o autor aponta, como processo de conflitos que a globalização provoca. $\mathrm{Na}$ obra de Rochelle Costi(1961) fica evidente que a produção da artista está alinhada com sua poética, distante dessa forma de operar do mercado. A artista desenvolve o trabalho na investigação de questões que são inerentes ao seu universo, sua construção e não ao mercado aqui explicitado.

Em outro momento, Canclini (2008, p.102-104) traz a questão da "dissolução das monoidentidades", pois questiona a noção eo discurso que se tinha com relação à várias questões. Dentre elas, pode ser destacada a catergoria etnia. Essa ideia de unir as pessoas por categorias, nos 
grandes centros, como São Paulo, que é o local que a artista produziu a Série aqui analisada, não consegue mais ter sustentação. Retomando o exemplo da etnia, é pontual entender que com mais de 2 milhões de habitantes, várias delas estão no processo que o autor trata como hibridação,ou seja, na dissolução das fronteiras que eram marcadas até o início do Século XX. Diante da obra de Rochelle Costi é latente o tratamento dessas questões. Ao apresentar um traço tão pessoal como os quartos de pessoas "anônimas", ela visibiliza as narrativas individuais. As "monoidentidades" estão visibilizadas não como o "Estado-nação" a qual Canclini (2013) se refere, mas com a explicitação dos objetos que compõem o ambiente que são fotografados.

Para comparação da imagem 1, escolheu-se outra fotografia da Série Quartos-São Paulo de 1998, cuja composição apresenta outra configuração: um quarto que pertencente a uma pessoa com outro status social, inferência realizada a partir dos elementos que aparecem na imagem. Como abordado anteriormente, a artista selecionou propositadamente bairros com diferentes classes sociais. $\mathrm{Na}$ imagem 4, é possivel notar que os objetos dispostos no ambiente estão mais próximos do que podemos chamar de suas funcionalidades. Essa funcionalidade é apontada pela disposição no ambiente: a cadeira de estudo em frente uma pilha de livros e colocada sob uma luminária. Um painel com fotografias, tapetes ao lado da cama, a própria mesa que suporta um rádio e ao lado uma pilha de $c d s$.

Figura 4. Rochelle Costi.Quartos-São Paulo, 1998.

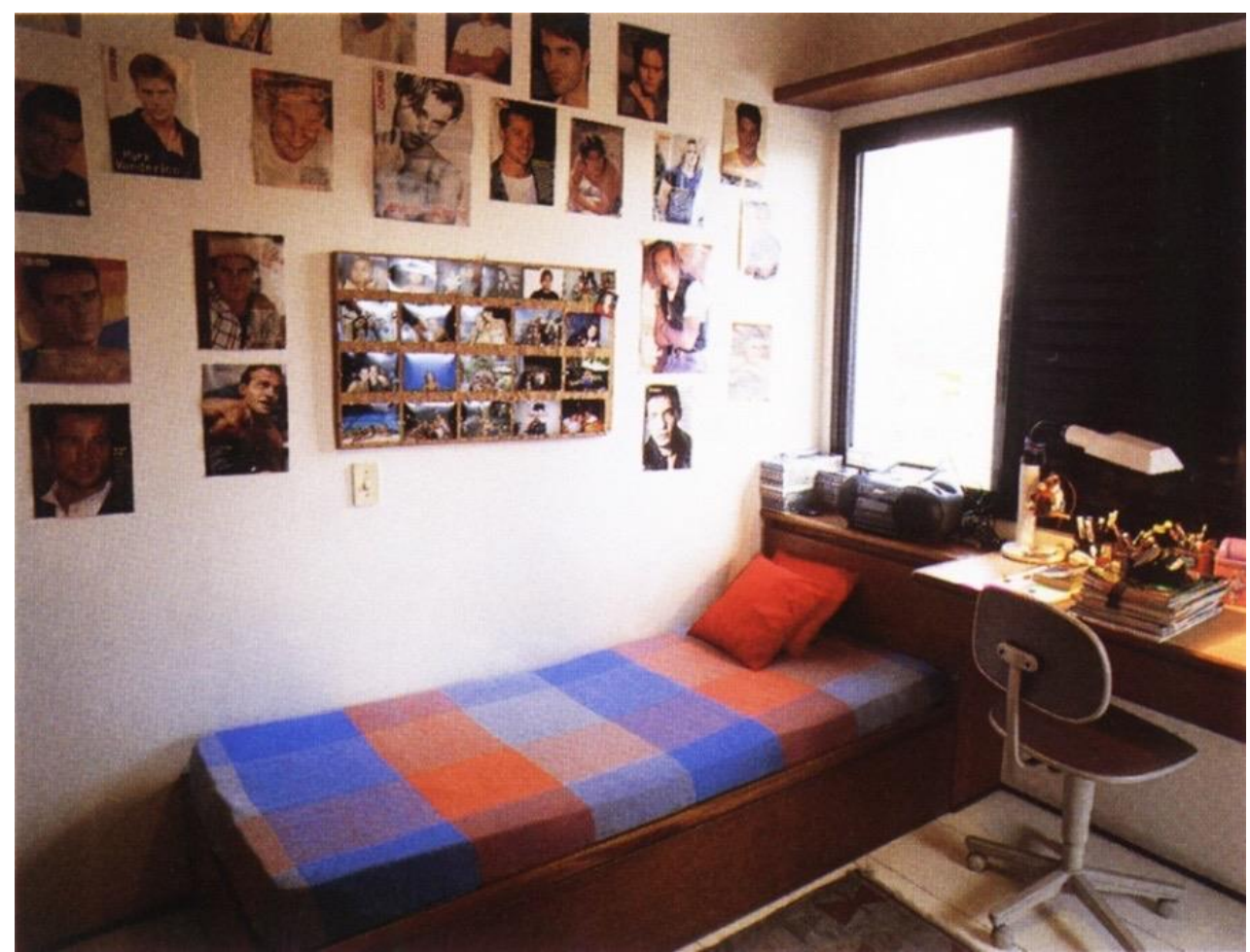

Fonte: http://rochellecosti.com/Quartos-Sao-Paulo-1998. Fotografia Analógica, 1x80m x 2,20m.

Dimensionar todos os detalhes da imagem, direciona o olhar para as proposições de Canclini (2013), que aponta como a arte processa essas narrativas singulares, a possibilidade da construção individual, da memória, tanto social quanto pessoal, na construção de uma imagem. Pensar esses objetos em cena, permite ainda localizar sua produção em seu tempo-espaço. O design desses 
móveis indica a construção de um período diferente do atual. Por ser uma fotografia analógica, entende-se aquilo que Barthes (1984) denominou como "isso-foi", citado anteriormente, é parte dessa construção. A imagem também oferece elementos qua apontam a construção social desse espaço, bem como a própria imagem, a fotografia analógica, que por ser física e não digital configura-se também como cultura material.

Nas imagens 1 e 4, as pessoas não estão em cena, portanto, abrem-se possibilidades de construções de narrativas no e pelo espectador, questionando sobre as pessoas que habitam esses espaços, por exemplo. Nesse sentido, a obra não está fechada em um conceito, mas verdadeiramente expande a possibilidade de criação, pois a cada leitura, novas possibilidades se apresentam. Inclusive, terá novos sentidos dependendo do contexto que for exposta.

\section{Objetos de Arte e Artefato}

Perceber a trajetória desses quartos e cada objeto que os compõem, permite acessar outro tempo-espaço que nos remete aos valores que são ressignificados por esses objetos, muitas vezes, quando se acessa a memória desse período. Alguns desses objetos hoje estão completamente obsoletos, mas indicam várias questões, como a tecnologia do período, os usos, as cores, as formas, o pensamento estético, o pensamento de mobiliário, que denota o jeito de morar, a noção de espaço, o crescimento da cidade e as formas de se relacionar com eles. Um exemplo que pode ser explicitado para essa obsolescência é o aparelho que toca $c d s$. Os dispositivos que armazenam músicas na atualidade são celulares, pen drives, entre outros portáteis, ou mesmo virtuais, mostrando que esse aparelho faz parte de outro período da História. Mendes (2012) discute sobre esse trajetos dos objetos apontando para a temporalidade deles:

\footnotetext{
Transformando-se, objetos podem acompanhar um tempo vivido em espaços, que se torna memória e história. Ao insistirem em perdurar, perdem seus valores de mercadoria e passam a ter outros valores acionados (como os emocionais) e, desmercantilizados, caracterizam-se como peças singularizadas de coleção (domésticas ou de museus). Práticas que prolongam a vida de produtos inserem-nos em uma longa temporalidade, perdendo o caráter efêmero que os condena ao descarte, a exemplo dos desvios relacionados aos circuitos da moda. Isto não significa que, em algum momento, não possam volta a ter valores monetários acionados e retornar aos circuitos de circulação. (MENDES, 2012, p.31)

No exemplo citado percebemos que muitos desses aparelhos hoje povoam feiras de objetos
} e mercado de pulgas em todo o Brasil. Na obra de Rochelle Costi essa ressignificação e volta ao mercado citada pelo autor também recorrente, pois a artista coleciona objetos, e em algumas obras esses objetos estão presentes. Após fotografados ou expostos, voltam a figurar as coleções da artista.

\section{Considerações Finais}

Este artigo inicia estabelecendo a relação da Arte, do Design e do Artefato, refletindo sobre o que seria um objeto de arte, não categorizando-o. Vimos que é difícil manter uma categoria com fronteiras rígidas quando se trata do objeto de arte, principalmente quando percorremos o trajeto da construção dessa obra e dos próprios objetos que a compõe. 
Nesse sentido é complexo se estabelecer um lugar estanque para este objeto como obra de arte ou como artefato, pois sendo obra de arte oferece as questões que a classificam como tal. Seriam elas: foi exposta na XXIV Bienal Internacional de Arte de São Paulo, tem a assinatura da curadoria de Paulo Herkenhoff, traz o discurso da tradição da História da Arte, tem o pensamento estético da artista, é objeto de arte no sentido de associação ao pensamento de Danto (2005).

Igualmente nota-se o poder de artefato que carrega, associando à teoria de objetificação de Miller (2013) que permite entender como o objeto se constitui na relação com o humano, que também é constituído por esse objeto. É nessa relação que são construídos esses significados e por isso, são mutáveis e negociáveis, acionados ou não, podendo ser outras coisas, em determinados momentos da trajetória no mundo social.

Esses objetos apresentados por Rochelle Costi são parte do cotidiano, que na composição perdem suas funções e passam a ser a imagem do objeto, formando ainda a fotografia, também categorizada como arte. Dessa forma a funcionalidade do objeto perde completamente seu caráter inicial e passa a ser esse objeto de investigação e constituição social, desse ser humano, que habita esse espaço e que está ausente na imagem. Esses mesmos objetos acionam memórias, lugares, tempo, nessa nova configuração, transpondo a questão de ready-made colocada anteriormente, pois ele não está fisicamente presente, como está em um ready-made, mas sim transfigurado.

Os objetos nas imagens apresentados são parte do cotidiano, que podem ser considerados como populares. Martins (2017, p. 15-16) analisa a questão da fotografia e aponta que:

A cultura popular da imagem é uma cultura que considera lícita a transformação de certos momentos da vida e certas situações em imagem fotográfica e que considera que outros momentos e situações devem ser interditados à invasão do fotógrafo e dos bisbilhoteiros em geral. Permissões e interdições à fotografia acompanham os cuidados, até rituais, em relação ao olho e ao olhar da vida cotidiana.

Ao pensar as questões aqui evidenciadas, é notório que a complexidade apresentada no trabalho de Rochelle Costi (1961) na Série Quartos-São Paulo, 1998, não se encerra com essas discussões. Os objetos apresentados aproximam a cultura material da discussão do objeto de arte, que trabalha com elementos da cultura material há muito tempo, ganhando novo fôlego como debate, no século XX e XXI.

Muitos antropólogos utilizam a fotografia para pensar o aspecto híbrido "que permite a conexão entre arte, conhecimento e informação (NOVAES, 2015, p.9)." A arte possibilita a abertura da discussão dessas questões mediadas pelo processo tecnológico da fotografia, nesse caso, entre outros mecanismos. Novaes (2015) aponta que "A fotografia igualmente nos ajuda a refletir sobre processos de construção da realidade, com os quais as diferentes formas de expressão artística sempre lidaram (2015, p.18)."

O conceito de hibridação utilizado por Canclini (2013) se aplica a esse artigo, pois o autor entende "por hibridação processos socioculturais nos quis estruturas ou práticas discretas, que existiam de forma separada, se combinam para gerar novas estruturas, objetos e práticas (2013, 
p.XIX)." Portanto, o que se envidenciou ao longo de todo o artigo, destacando a produção da artista no final da década de 90 do Século XX.

Nesse sentido, o objeto de arte que é a fotografia dos artefatos ou objetos de design que a artista apresenta em uma nova composição, são problematizados no artigo como cultura material, explorando a teoria crítica de design que entende que os processos de uso desses objetos no universo cultural que os constituem e os significam.

\section{REFERÊNCIAS}

BARTHES, Roland. A Câmara Clara. Rio de Janeiro: Nova Fronteira, 1984.

BEUYS, Joseph. Joseph Beuys (atividade cultural 07).
https://artenomundo.wordpress.com/2010/11/15/joseph-beuys-atividade-cultural-07/. Acesso: 22/03/2018.

CANCLINI, Nestor G. Consumidores e Cidadãos: Conflitos multiculturais da globalização. Rio de Janeiro, Editora UFRJ, 2008.

A Sociedade sem Relato: Antropologia e Estética da Iminência. São Paulo: Editora da Universidade de São Paulo, 2016.

Culturas Híbridas: Estratégias para Entrar e Sair da Modernidade. São Paulo: Editora da Universidade de São Paulo, 2013.

CARDOSO, Rafael. Design para um mundo complexo. São Paulo: Cosca Naify, 2013.

DANTO, Arthur. A transfiguração do lugar comum. São Paulo: Cosac Naify, 2005.

ROCHELLE Costi. In: ENCICLOPÉDIA Itaú Cultural de Arte e Cultura Brasileiras. São Paulo: Itaú Cultural, 2018. Disponível em: <http://enciclopedia.itaucultural.org.br/pessoa22077/rochellecosti>. Acesso em: 27 de Mar. 2018. Verbete da Enciclopédia.

GEERTZ, Clifford. O Saber Local: novos ensaios em Antropologia Interpretativa. Petrópolis: Vozes, 2009.

GOMES, L...IN: APPADURAI, Arjun. A vida social das coisas. As mercadorias sob uma perspectiva cultural. Niterói: Editora da Universidade Federal Fluminense. 2008

JOLY, Martine. Introdução à Análise da Imagem. Campinas: Papirus Editora, 2000.

KOPYTOFF, Igor. A Biografia Cultural das Coisas: a mercantilização como processo. IN: APPADURAI, Arjun. A Vida Social das Coisas. As mercadorias sob uma perspectiva cultural. Niterói: Editora da Universidade Federal Fluminense. 2008. pp. 89-121.

MARTINS, José de Souza. Sociologia da Fotografia e da Imagem. São Paulo: Contexto, 2017.

MENDES, Mariuze D. Cultura Material: trajetórias sociaisde artefatos em contextos materiais e culturais de produção, circulação e consumo. In: QUELUZ, M.L.P. Design \& Cultura Material. Curitiba: Ed. UTFPR, 2012. Pp. 15-34. 
MILLER, Daniel. Treco, troços e coisas: estudos antropológicos sobre a cultura material. Rio de Janeiro: Zahar, 2013.

NOVAES, Sylvia C.(org). Entre arte e ciência: a fotografia na Antropologia. São Paulo: Edusp, 2015.

OITICICA, Hélio. Exposição em São Paulo. http://g1.globo.com/Noticias/PopArte/0,,MUL15368707084,00- EXPOSICAO+EM+SAO+PAULO+REUNE+CEM+OBRAS+DE+HELIO+OITICICA.html. Acesso em: $21 / 03 / 2018$. 